\title{
LA CIRCULACIÓN DE LAS AGUAS Y LAS DIFICULTADES DE AVENAMIENTO EN EL CORREDOR DE ALMANS A
}

\author{
Gabino Ponce Herrero
}

\section{RESUMEN}

El Corredor de Almansa constituye una comarca situada a caballo entre las cuencas vertientes del Júcar, Segura y Vinalopó, sin que ninguno de sus cursos fluviales afluya a esos ríos. Se trata, pues, de una gran área endorreica donde son frecuentes las lagunas, debido a las condiciones estructurales y morfológ i cas del relieve, así como a las características de su clima. La carencia de avenamiento exorreico se resuelve, con frecuencia, mediante desagüe hipogeo, lo que ha dado origen a dolinas y simas kársticas.

\section{ABSTRACT}

The Corredor de Almansa is a region situated among the valleys of the Júcar, Segura and Vinalopó rivers none of its watersheds flowing into those rivers. Thus, this is a great endoreic zone where lagoons are very oftendue to the structural and morphological conditions of the relief and the characteristic of its climate the lack of exoreic draining is often salved by subterraneam drainage wich has originated doline and karstic abyss.

El Corredor de Almansa es una comarca natural, situada en el extremo oriental de la provincia de Albacete, que ofrece una extensión de 1.159'4 $\mathrm{km}^{2}$, distribuidos entre cinco municipios: Almansa, Alpera, Bonete, Caudete y Montealegre del Castillo.

La comarca constituye un Corredor que pone en comunicación el Valle el Vinalopó con los altiplanos de Albacete, hecho que le confiere una morfología de transición entre las tierras mediterráneas y el paisaje de la submeseta meridional. Desempeña un destacado papel caminero entre el interior peninsular y el litoral, 
vía obligada en las comunicaciones entre Alicante, Valencia y Murcia, como ruta exclusiva hasta el siglo pasado y hoy alternativa del camino litoral.

Su altitud se sitúa entre las isohip sas de 500 y $1.200 \mathrm{~m}$, con unas cotas medias en torno a los $700 \mathrm{~m}$, en un área donde entroncan tres grandes dominios estructurales. La mitad meridional de la comarca está formada por varias alineaciones montañosas de dirección SW-NE (sierras del Cuchillo, Lácera y de la Oliva), que delimitan una serie de valles corredores intercalados: valle de Caudete, de Montealegre y de Los Derramadores entre otros. El ángulo nororiental se encuentra estructurado por pliegues montañosos de dirección NW-SE, esto es, en sentido inverso a los anteriores, configurando la Serranía de Almansa, que enlaza con los relieves del Macizo del Caroig ya en tierras valencianas. Por último, el sector noroccidental constituye una serie de altiplanos escalonados, caracterizado por un relieve fracturado con fosas y bloques elevados (Mugrón, Muela de Alpera, Punta de Gira Valencia y otros) y representa ya la transición a las vastas llanuras del centro albacetense.

En la comarca se dan, asimismo, unas condiciones de transición entre el clima mediterráneo litoral y el mediterráneo continentalizado. Desde el punto de vista térmico, las temperaturas medias de enero rondan los $5^{\circ} \mathrm{C}$ y las de julio los $23^{\circ} \mathrm{C}$. Aspecto a destacar es el de la amplitud térmica absoluta, que llega a $60,2^{\circ} \mathrm{C}$ en Almansa, debida a las esporádicas irrupciones de aire polar en invierno y de aire cálido del Norte de África en verano, masas que extreman los registros térmicos. Además, los contrastes acusados aparecen también en el transcurso del día por el intenso caldeamiento diurno de las masas de aire y la fuerte irradiación nocturna.

Las precipitaciones son escasas en general y oscilan entre los $353 \mathrm{~mm}$ de Montealegre y los $552 \mathrm{~mm}$ de Alp era, con una media en Almansa en torno a los $370 \mathrm{~mm}$. Ahora bien, al igual que en todo el sureste peninsular, las lluvias presentan unos elevados coeficientes de irregularidad, 4'3 en Almansa, y se encuentran muy mal repartidas a lo largo del año, período en el que se observa un mínimo pluviométrico en verano, que no llega a ser muy acusado, ya que en Almansa se recoge un total de 76' $1 \mathrm{~mm}$ en los meses estivales (que sup onen el 20'6\% de las lluvias anuales), debido a los altos registros de los primeros días de junio, cuando se dan las últimas lluvias del ciclo primaveral. La primavera y el otoño aparecen reflejados como dos máximos que destacan de manera clara respecto al mínimo veraniego. La primavera es la estación más lluviosa, recoge entre el 30\% y el 35\% de la precipitación total (112’3 mm o el 30’5\% en Almansa. El máximo secundario de otoño alcanza 105’ 4 mm o el 28’6\% de las lluvias y el valor más bajo, similar al del verano, se registra en invierno, con 74’8 mm o el 20’3\%.

Ahora bien, hay que indicar que esos volúmenes de precipitación en realidad se registran en unos pocos días durante el año, ya que las lluvias se caracterizan por su carácter torrencial y su fuerte intensidad horaria, de manera que son los intensos aguaceros, de unas pocas horas de duración, los determinantes fundamentales de esos registros anuales.

En el plano hidrográfico se comprueba la inexistencia de avenamiento exorreico claro de las aguas. Situada a caballo entre las cuencas vertientes del 


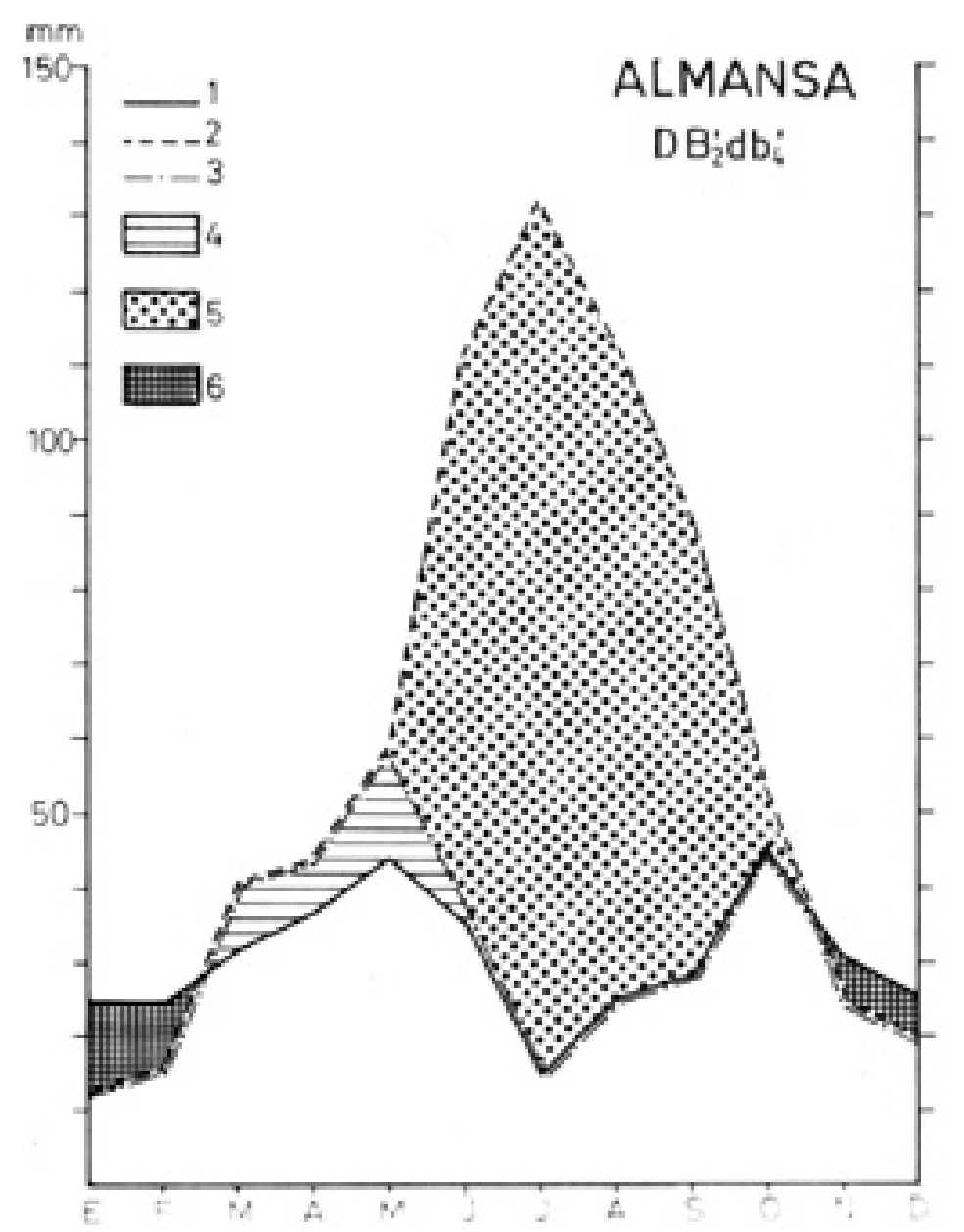

FiguRA 1. Climograma de Thornthwaite: 1. Precipitaciones; 2. evapotranspiración potencial; 3. evapotranspiración real; 4. utilización de la reserva hídrica; 5. déficit de agua; 6. superávit.

Júcar, por el Norte, del Vinalopó, por el Sureste, y del Segura, por el Suroeste, la comarca no cuenta con ningún curso fluvial afluente a esos ríos. Todas las ramblas, barrancos y manantiales desaguan en los fondos de valle, en cubetas endorreicas frecuentemente encharcadas, que han dado lugar a la formación de importantes lagunas. El único curso con nivel de base en el Mar, el Barranco del Malecón (afluente del Júcar), cuenta con una derivación desde principios del siglo XIV, la Acequia de Alpera, que conduce su escaso caudal hacia la cubeta endorreica de Almansa.

\section{La circulación de las aguas}

\subsection{Los manantiales}

La configuración del relieve en la comarca ha destacado en altura una serie de materiales calcáreos, calizas y areniscas del Cretácico y Mioceno, que constituyen 
mesas y sinclinales permeables donde las aguas se infiltran hasta llegar a un estrato de arcillas o margas. Además, la tectónica ha trazado una apretada red de diaclasas que, en ocasiones, han afectado a los mantos de agua, dando origen a manantiales, y otras veces ha sido el karst el causante de las surgencias. Todo ello hace de la zona un área donde han sido frecuentes las fuentes. No obstante, en la actualidad son muy pocas las que siguen manando, debido a la captación de caudales subterráneos mediante pozos y galerías que han provocado el descenso del nivel piezométrico, dejando «colgadas» y sin alimentación muchas de las antiguas surgencias.

En Almansa son abundantes los pequeños manantiales de naturaleza kárstica, como los de la Fuente de Cañolas, Fuente del Borreguete, Fuente de M iralcampo y Fuente de Mari Hernández, que brotan en la línea de contacto entre el paquete de calizas y dolomías del Cretácico Inferior y las arcillas y margas de la Facies Utrillas. En Hoya Matea, la configuración de una cuenca artesiana hace brotar en su fondo una serie de manantiales en forma de chortales. En el sinclinal colgado de Sugel parte del manto acuífero brota de las calizas del Albiense a partir de la fractura que atraviesa el sinclinal de manera perpendicular y que aprovecha la Rambla de Sugel en su descenso hacia el llano. Pero son las aguas de Zucaña las que han aportado tradicionalmente may ores caudales, que proceden de la gran cuenca de recepción que forma el sinclinal colgado de Valparaíso, con el techo compuesto de calizas y conglomerados del Langhiense, un estrato suby acente de dolomías del Cenomaniense y el nivel de base marcado por las arcillas y margas de la Facies Utrillas; una línea de fractura, aprovechada por la Rambla de los Molinos, sirve de canal de avenamiento de parte del acuífero originando surgencias, hoy reguladas, en el paraje de Zucaña. Aguas abajo, en el mismo seno de la rambla, aparece un nuevo nivel de avenamiento a partir de otra falla, que secciona el paquete dolomítico y el de arcillas infrayacente, y da lugar a una surgencia en la zona de contacto de ambos, manifiesta en forma de hilillos de agua que caen por el pequeño salto de falla, y reciben el significativo nombre de «La Mearrera».

En Alpera existió una fuente en la Cañada de Pedro Ponce capaz para mover un molino, pero las más importantes son las surgencias de Las Fuentes en la Cañada de Pajares, donde cinco manantiales: la Redonda, las Dos Hermanas, el Casar, la de Diego y la del Álamo; han permitido el abasto doméstico y agrario de este municipio, al tiemp o que son las princip ales tributarias del embalse de Almansa. En la actualidad el agua se extrae mediante una mina, con un caudal medio de $6 \mathrm{l} / \mathrm{sg}$.

En el resto de la comarca, aun cuando ha habido importantes manantiales, en la actualidad no queda ninguno en funcionamiento por la sobreexp lotación de los acuíferos.

\subsection{Las ramblas}

No existe en el Corredor de Almansa ningún curso fluvial permanente. La red hidrográfica está formada por un conjunto de barrancos y ramblas casi siempre secos, que sólo excepcionalmente conducen agua, durante algunas horas, 


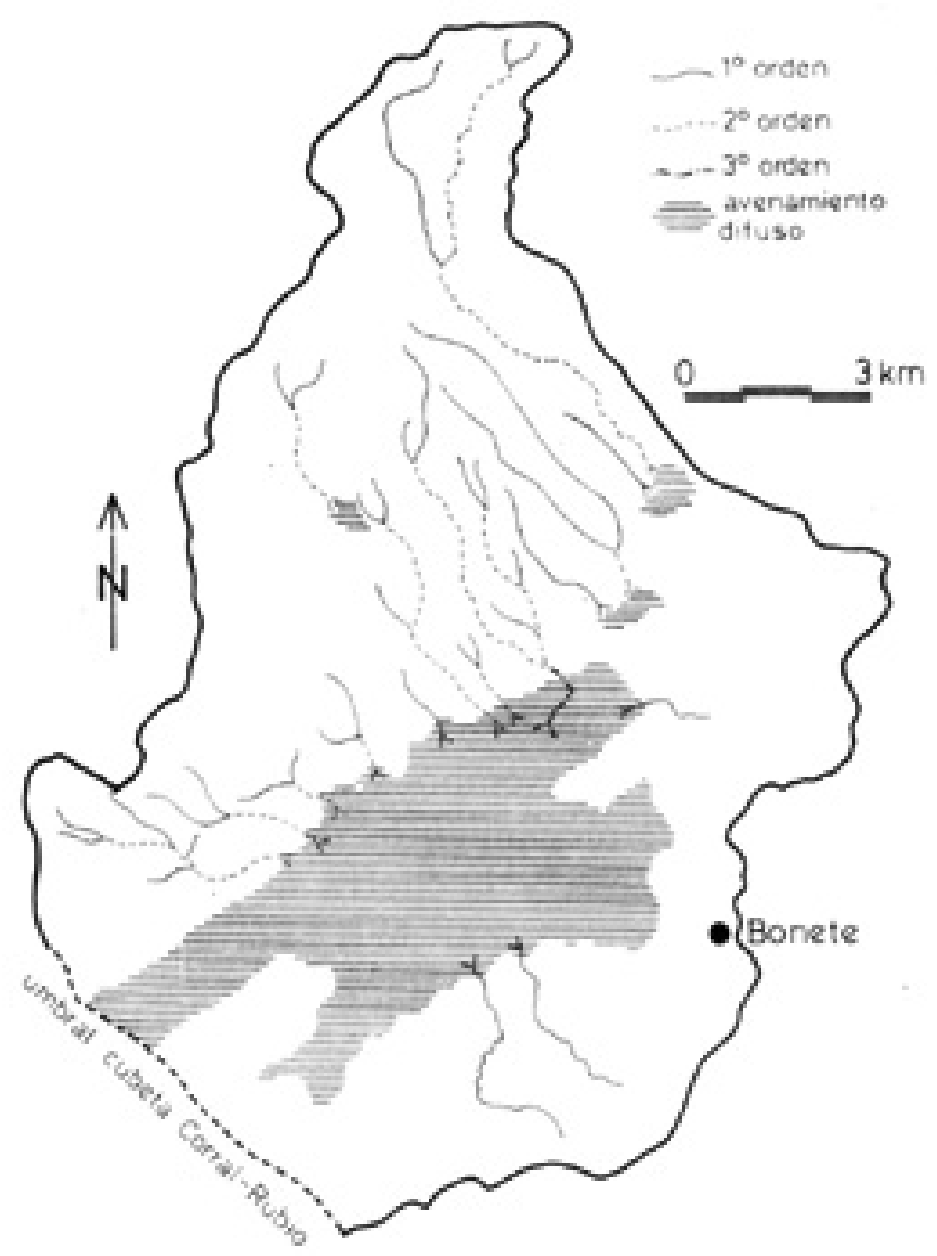

FIGURA 2. Morfometría cuenca endorreica de Bonete.

después de las lluvias de fuerte intensidad horaria. Son pues auténticas ramblas mediterráneas, de régimen intermitente y torrencial, que ven interrumpidos sus largos períodos de sequía por esp asmódicas avenidas en las que sus caudales cobran, durante unas horas, valores excep cionales para este ámbito.

La malla de cursos fluviales se encuentra subordinada a las disposiciones de las estructuras geomorfológicas de la comarca. Todo los cauces tienen un nivel de base local, esto es, desaguan sobre el fondo de los valles, en las cubetas endorreicas que jalonan la comarca; a excep ción de la alineación Cañada de Pajares-Barranco del Malecón, con un nivel de base marcado por el mar a través de la red afluente del Júcar, aunque también padece en algunos tramos la característica falta de pendiente que afecta a los otros cursos.

Son cuatro las áreas endorreicas que recogen las aguas en la comarca. La más occidental es la de la cubeta de Bonete, cuenca cerrada ubicada en la mitad septentrional de la Fosa de Corral-Rubio, con una extensión de 184’ 4 km², flanqueada por la Punta de Gira Valencia al norte y por la Loma de Santo Domingo al Sur (pequeña elevación en el centro de la fosa que sirve de umbral entre las cubetas de Bonete y Corral-Rubio. La red afluente está poco jerarquizada y 
configura una dep resión anastomosada, con un marcado carácter hipogeo, cerrada por la isohipsa de $670 \mathrm{~m}$, con un elevado nivel freático debido al substrato arcilloso, que provoca un encharcamiento frecuente de la superficie.

En el centro del valle corredor de Almansa se encuentra el área endorreica más extensa, articulada en tres grandes cubetas alineadas, con una pequeña cuenca menor intermedia. Es en esta zona donde desaguan las ramblas más importantes de la comarca. El curso más largo es el de la alineación Vallejo del Chopo-Cañada del Charco-Rambla del Pantano, con una longitud de 50,5 km desde su cabecera en El Relumbrar, a 1.010 m, hasta el llano de Almansa a $700 \mathrm{~m}$, que fijaba su antiguo nivel de base, localizado en la actualidad 4'5 km aguas arriba, en el embalse de Almansa, a unos 750 m de altitud; cuenta además esta alineación con la mayor cuenca vertiente, que cubre 331 ' $7 \mathrm{~km}^{2}$.

La Rambla de Sugel es el principal colector de la Serranía de Almansa, con una longitud de 15'5 km en su eje princip al, que recibe las aguas de una cuenca de $56 \mathrm{~km}^{2}$ y las conduce hacia la cubeta de Las Juncadas, en las proximidades de la ciudad de Almansa. También desemboca en ese paraje la Rambla de Los Molinos, que avena el paquete de plegamientos de dirección bética, fracturados y dislocados, situado entre Almansa y la Sierra de la Oliva; con una cuenca vertiente de 55'9 $\mathrm{km}^{2}$ y un curso principal de $12 \mathrm{~km}$ de longitud. Esta rambla lleva agua en algunos tramos debido a los nacimientos que aparecen en su seno, como el de La Mearrera.

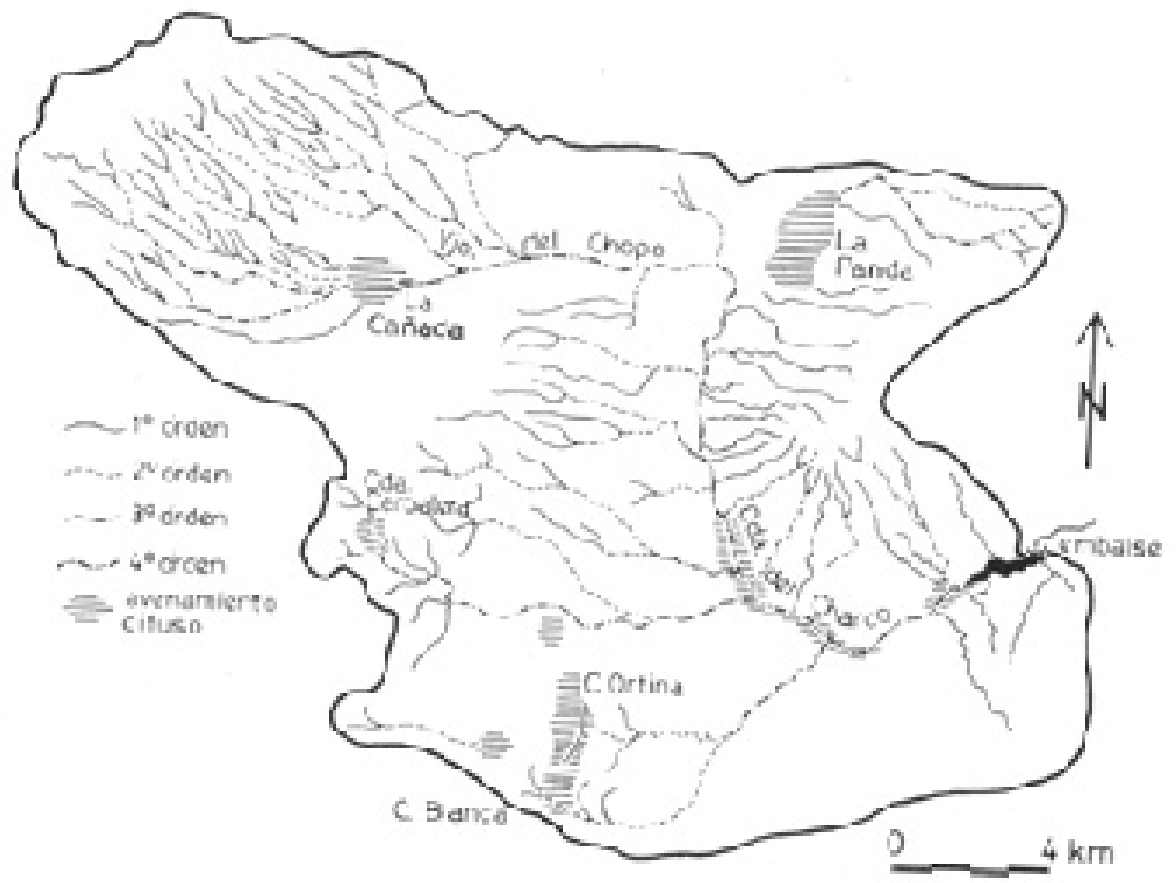

FiguRA 3. Morfometría. Vallejo del Chopo-Cda. del Charco. 
En el cuadrante suroccidental de la comarca, la Rambla del Agua Salada, con una cuenca de recepción de 276’5 $\mathrm{km}^{2}$, avena casi todo el término municipal de Montealegre y desagua sobre la confluencia de los glacis del Arabí y Sierra Lácera, en un área anastomosada donde no aparecen cauces definidos.

En la Serranía de Santa Bárbara, una serie de barrancos y ramblas engendrados en el conjunto serrano del Sur de Almansa, atraviesan el imponente eje anticlinal de Sierra de la Oliva, por algunas fracturas transversales, y se precipitan sobre la cubeta semiendorreica de la Huerta de Arriba, en Caudete, avenada por dos portillos, origen de dos pequeñas ramblas, la del Molino y la de San Vicente, que desaguan finalmente en la gran cuenca endorreica de los Saleros de Villena, ya en el Alto Vinalopó.

\section{El endorreísmo}

Se ha señalado el marcado carácter local de los cursos fluviales del Corredor, conviene por ello determinar los aspectos generatrices de esas cuencas cerradas.

El Corredor de Almansa manifiesta un endorreísmo generalizado, de características intermedias entre el típico endorreísmo continental manchego ${ }^{1}$, debido a la horizontalidad del relieve y a la gran aridez ${ }^{2}$, y el endorreísmo del interior de las provincias de Alicante y Murcia, ocasionado por la presencia de valles corredores de dirección bética, a menudo taponados por glacis o conos de deyección, y estrechamente ligados a afloramientos triásicos de mat eriales imp ermeables ${ }^{3}$.

La comarca participa en su mitad occidental, efectivamente, de los rasgos típicos que han dado lugar a la frecuente presencia de lagunas y lagunillas en la provincia de Albacete. Abundantes muestras aparecen en la depresión de La Higuera (Corral Rubio), a tan sólo dos kilómetros del límite municipal de M ontealegre, en Corral-Rubio, como prolongación meridional de la cubeta de Bonete, y en Higueruela, próxima también a esta cubeta. No obstante, dentro de la comarca tan sólo se forman extensas charcas, de corta evolución en el tiempo -algunas semanas-, ligadas a los aguaceros de fuerte intensidad horaria de otoño y primavera. En la mitad oriental de la comarca, zona de tránsito hacia las depresiones levantinas, el endorreísmo reviste mayores proporciones; son frecuentes las grandes lagunas -en la actualidad desecadas- que se inundan ocasionalmente tras los aguaceros equinocciales.

Las causas de estos fenómenos radican en una serie de aspectos:

I) Estructurales. De manera esencial, la comarca se articula según tres formas básicas, cada una de ellas con un destacado papel en los procesos de endorreísmo:

a) Un juego de fosas y bloques elevados, con dirección SW-NE y E-W, secciona la mitad occidental de la comarca y da lugar a un relieve germánico de estructuras tabulares. Los cursos fluviales son muy escasos, normalmente sólo aparecen salvando los saltos de falla, como canales de avenamiento de las superficies de los bloques elevados, y se pierden al discurrir sobre la fosa o confluyen en las áreas más deprimidas, donde se abren en numerosos hilillos que acaban en una 


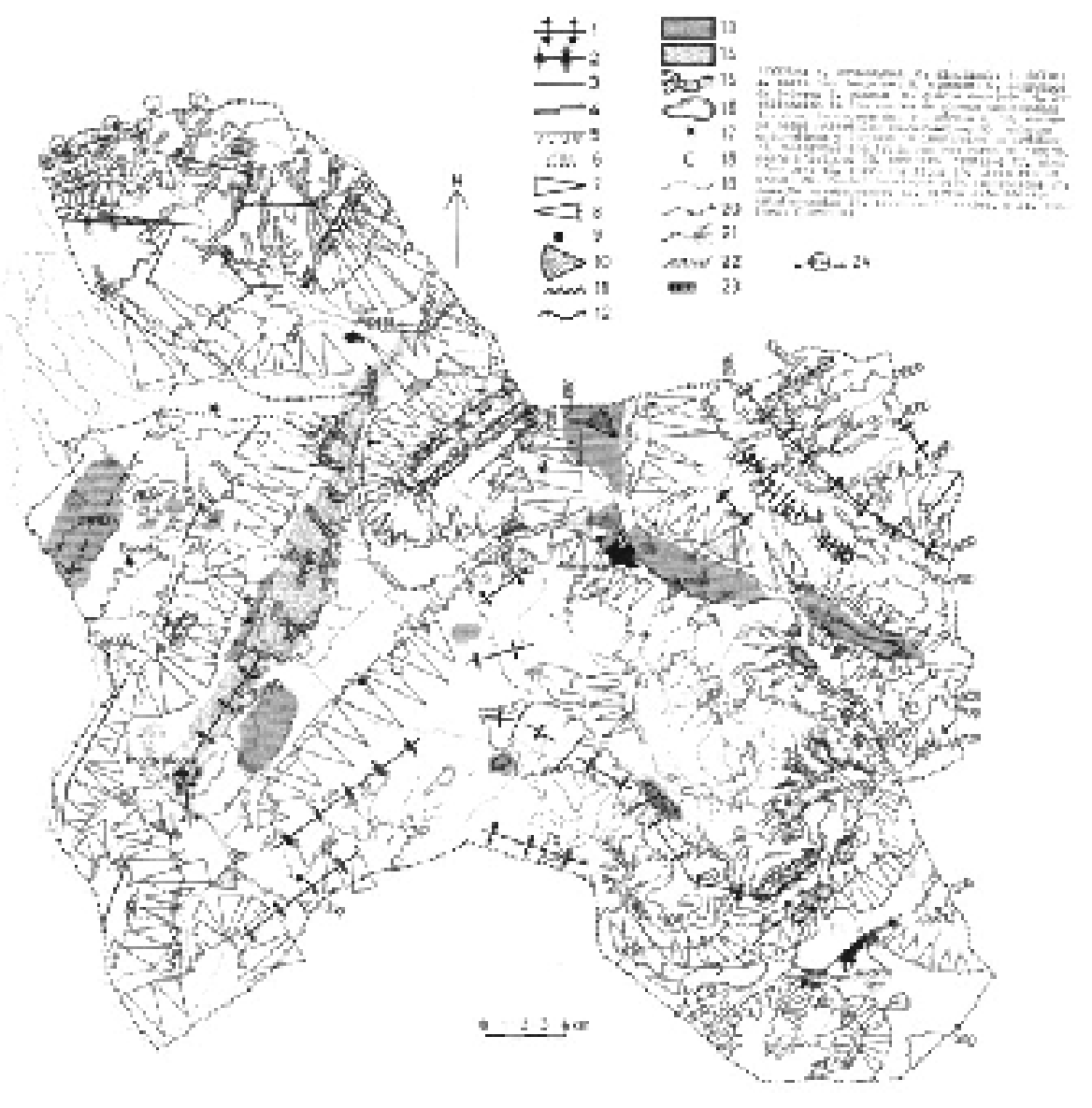

FIGURA 4. Mapa geomorfológico de la comarca.

cubeta anastomosada, donde la circulación tiene un marcado carácter subálveo -es el caso de la cubeta de Bonete-. Por otra parte, tanto en la superficie de los horst como en la de las fosas, en los vastos interfluvios de escasa o nula gradiente vertical, las suaves ondulaciones del terreno configuran pequeñas cuencas cerradas, donde la precipitación recogida forma extensos charcos o se filtra, según la naturaleza del roquedo, configurando áreas sin avenamiento organizado, que dan a la zona un elevado grado de arreísmo. Cubetas de este tipo son las de Hoya Morena, Hoya Escobosa, Hoya Labrada y Las Riscas, alineadas en la superficie del horst de Bonete, 
ahondadas por disolución kárstica sobre las calizas del Kimmeridgiense, todas ellas con un avenamiento subterráneo tip o dolina. Sobre la fosa, la presencia de una cubierta arcillosa de edad plio-pleistocena impermeabiliz a las pequeñas cuencas y da lugar a los enormes charcos, desecados por evapotranspiración, que caracterizan a la fosa de Corral-Rubio durante los momentos equinocciales.

b) Un afloramiento triásico, que ha rasgado las estructuras preexistentes y ha taponado las áreas de desagüe. Es el caso de la alineación de materiales del Trías que aflora entre Montealegre y Alpera, a manera de anticlinal arrumbado de SSW a NNE sin llegar a rasgos diapíricos. La pendiente general, y en consecuencia el avenamiento, se orienta de $\mathrm{W}$ a E, entre el horst de Bonete y la depresión de Almansa, pero los resaltes de la charnela desventrada del Trías se interponen transversalmente y originan una alargada cuenca endorreica, entre el horst y el Trías, compartimentada en pequeñas cubetas, algunas avenadas de manera natural, al haberse labrado un p ortillo kárstico a través del paquete triásico -como la cubeta de Casa Blanca-, otras artificialmente, mediante azarbes -como la de Casa Ortina-, y las más configurando cuencas cerradas, de entre las que destaca la Hoy a Rasa, con 2'95 km² de superficie de inundación, situada en la margen oriental del afloramiento triásico pero con las mismas características que las del flanco occidental.

Todas ellas ap arecen encharcadas durante semanas tras las lluvias de fuerte intensidad horaria debido al carácter impermeable de las arcillas pliopleistocenas y del Keuper. En ocasiones, el contacto con una de

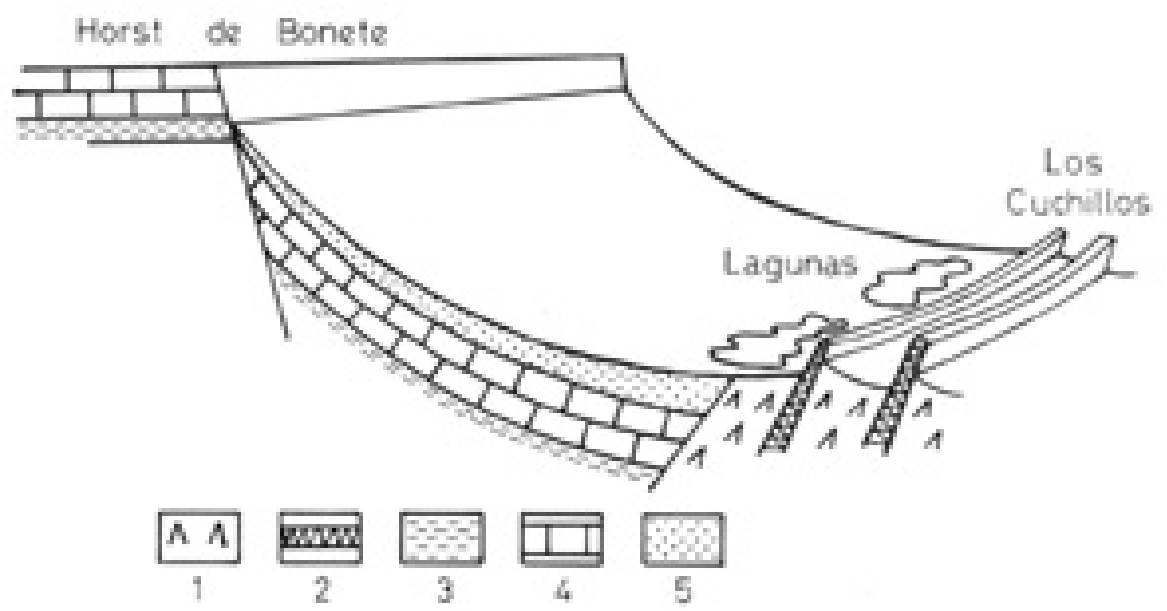

Figura 5. Bloque diagrama esquemático del g lacis de la vertiente oriental del horst de Bonete. Los materiales son: 1. arcillas del keuper; 2. calizas y dolomías del Muschelkalk; 3. arcillas del Cretácico Inferior; 4. Calizas del Aptiense; 5. arcillas del Villafranquiense. 
estas cubetas con las dolomías del Rethiense-Hettangiense o con las calizas y dolomías del Muschelkalk han dado lugar a la formación de simas, que las avenan de forma hipogea.

c) Un conjunto de materiales plegados que constituyen la mitad oriental de la comarca. En el ángulo NE son pliegues de dirección ibérica, esto es, NW-SE, y en el cuadrante SE de dirección bética, es decir, SW-NE.

Todos ellos configuran valles corredores, sometidos a una intensa tectónica que ha interrumpido su desarrollo longitudinal con saltos de falla y desgarres, cortando en ocasiones el avenamiento normal de los sinclinales, como sucede en la cuenca cerrada que da origen a la laguna de Sugel, en el seno de un sinclinal colgado; en las Hoy as de Catín, en un sinclinorio muy fracturado y dislocado, o en las cubetas de Botas y los Pozuelos, áreas deprimidas afectadas por pliegues, embutidas en polígonos de fracturas.

II) Morfológicos. Debidos a fenómenos desarrollados durante el Cuaternario:

a) Las acumulaciones de material detrítico en forma de glacis o de conos de deyección han contribuido a tap onar los valles corredores, individualizando sectores intermedios convertidos en cuencas cerradas. Esta acción se superpone de manera normal a la tectónica, que ha marcado las grandes directrices. Así el afloramiento triásico de carácter diapírico ha sido el causante de la apertura del gran valle estructural Ayora-Almansa, sobre el que los procesos de erosión y acumulación posteriores han compartimentado, con sus depósitos, una serie de cubetas alineadas de Norte a Sur según el rumbo del Trías.

En la comarca, la más septentrional de estas cubetas es la que da origen a la laguna de San Benito cuenca endorreica de unos $90 \mathrm{~km}^{2}$, con una sup erficie de inundación de aproximadamente 4'5 $\mathrm{km}^{2}$, enmarcada por la isohip sa de 680 m. Hacia el Norte, la cuenca queda sep arada por la rambla de La Peña, que vierte aguas al Júcar, por los depósitos cuaternarios en forma del glacis-cono que descienden de las estructuras cretácicas del Caroig. Por el Sur queda individualizada por la convergencia del glacis de La Atalaya y el gran cono de deyección de la Rambla del Pantano, que marcan un umbral a $685 \mathrm{~m}$ de altitud -entre Casa Mancorra y Casa La Estacada- en una línea W-E que señalaría aproximadamente la división de aguas entre la cubeta de San Benito y la de Almansa. En efecto, hacia el Sur las aguas convergen en la pequeña cuenca, de unas $18 \mathrm{Ha}$, situada en la huerta Norte de Almansa, cerrada p or la isohipsa de 680 $\mathrm{m}$, y en la actualidad enmarcada por la variante de la carretera N-430, el primer kilómetro de la carretera de Ayora y el Paseo de las Huertas en el casco urbano de Almansa.

A partir de la ciudad la alineación diapírica se orienta hacia el SE, y con ella el valle. El pitón de calizas y dolomías del Muschelkalk, sobre el que se asienta el Castillo de Almansa, configura un nuevo umbral en el centro de la depresión, que enlaza con el glacis de La Centinela por el Sur, y con el de Los Carasoles, por el Norte, separando la anterior de la 
extensa cubeta de Las Juncadas-El Saladar, abierta hacia el SE. Esta cubeta cuenta con una cuenca vertiente de $138^{\prime} 76 \mathrm{~km}^{2}$-en ella desaguan entre otras las ramblas de Sugel y Los Molinos- y con un lecho de inundación de 4’02 km² circundado por la isohipsa de $687 \mathrm{~m}$. Su límite suroriental viene marcado por el afloramiento diapírico de Las Cabezuelas, levantadas en el centro del valle hasta los $760 \mathrm{~m}$ : de nuevo, el enlace con los glacis que descienden de las alineaciones cretácicas que flanquean la depresión actúa de divisoria de aguas, señalando un umbral a 697 m de altitud en El Ventorrillo, que separa ésta de la última cubeta endorreica del valle corredor de Almansa: La Hoy a de La Carrasca, de naturaleza distinta a las anteriores, ya que se trata de una fosa tectónica en las calizas del Albiense-aquí no ap arece el substrato triásico- tapizada e individualizada p or una serie de pequeños glacis, que han configurado una cuenca hidrográfica cerrada de 100'93 km², con un lecho de inundación de 1'62 km², cercado por la isohip sa de $650 \mathrm{~m}$. Su límite oriental lo constituye el umbral calizo del Puerto de Almansa, a 655 m de altitud.

En Caudete, dentro ya del ámbito de plegamientos de dirección bética, en el valle corredor situado entre Sierra de La Oliva, al Norte, y la alineación anticlinal Sierra del Cuchillo-Mateos, al Sur, los glacis-cono de la Sierra de La Oliva han dividido la depresión en dos cubetas a partir del umbral marcado por la convergencia del glacis de El Revolcador con el Cabezo de San Vicente, al W la cubeta de El Cañizar y al E la de la Huerta de Arriba. Ambas cuencas, cerradas en el Cuaternario, han conseguido labrar dos portillos sobre el glacis del anticlinal de Mateos: La Rambla de San Vicente y la Rambla del Molino respectivamente, por las que desaguan sobre el paraje de El Blanco, sector septentrional de la gran cuenca endorreica que dio lugar a la antigua Laguna del Rey -hoy desecada- ya en término de Villena.

De toda esta serie de cuencas morfológicas, las tres primeras, esto es, la de San Benito, la de Almansa y la de Las Juncadas-El Saladar, debido al Keuper infrayacente, presentan un lecho impermeable y son frecuentemente inundadas tras las lluvias equinocciales. La de Hoya de La Carrasca actúa como un sumidero kárstico, y en las demás las aguas apenas sí llegan a encharcar la superficie, debido a la importante circulación subálvea de las ramblas tributarias y al avenamiento hip ogeo.

b) La comarca se encuentra ubicada en la divisoria de aguas de las tres grandes cuencas hidrográficas de la región: al Norte la del Júcar, al Suroeste la del Segura y al Sureste la del Vinalopó. No obstante, no existe enlace con estos cursos fluviales salvo en el caso del Barranco del Malecón, que vierte al Júcar a partir de la red afluente de este río. Por ello, la erosión regresiva remontante provocada por el retroceso de las cabeceras de estos ríos y sus redes tributarias, con el nivel de base en el mar, no ha alcanzado al Corredor de Almansa, circunstancia que contribuye a perpetuar el endorreísmo de la comarca.

III) Climáticos. La carencia de un avenamiento exorreico queda explicada 
en parte por la existencia de unas acusadas condiciones de aridez. Las escasas precipitaciones y su marcada concentración en el tiempo determinan la ausencia de cursos de agua permanentes, que pudieran haber desbordado o encajado los umbrales endorreicos, lo que explica al tiempo el arreísmo del sector occidental de la comarca. La aridez de las tierras motiva una rápida infiltración de las aguas que discurren sobre materiales detríticos cuaternarios. De ahí que la may or parte de los cursos sean influentes, es decir, exp erimentan una pérdida constante de los caudales por infiltración en sus cauces. Ambos hechos son los condicionantes del comportamiento de las ramblas, cuyas aguas, cuando las llevan, se pierden sobre la superficie de los glacis y confluyen de manera subálvea en el fondo de las depresiones, formando cuencas hipogeas con un elevado nivel freático, mantenido por un substrato impermeable, formado normalmente por arcillas. Cuando las precipitaciones rebasan el umbral de saturación las aguas discurren en sup erficie y confluyen en el fondo de las cubetas, dando lugar a la formación de lagunas y lagunillas, cuya evolución está ligada a la permeabilidad del substrato y a la evapotranspiración. Así, las lagunas formadas por los aguaceros de otoño perviven durante más tiemp o -en ocasiones hasta el verano siguiente por las bajas temperaturas invernales, el dominio de un aire frío, desfavorables a la evaporación, y la ausencia en esos momentos de una cubierta vegetal. Por contra, las originadas por los chubascos de primavera duran menos, ya que las temperaturas van en ascenso y las plantaciones de cereales contribuyen con su transpiración a desaguarlas ${ }^{4}$.

\section{El avenamiento hipogeo}

Este tipo de fenómeno reviste considerable importancia en la comarca por la conjunción de una serie de aspectos positivos para su desarrollo, como es la presencia de un roquedo favorable a la disolución. Los grandes paquetes calizos del Cretácico constituyen la mayor parte del retablo montañoso del Corredor, también en el fondo de los valles son frecuentes los afloramientos de calizas ligados a extrusiones triásicas, e incluso sobre los propios materiales del Trías se desarrollan fenómenos de disolución. Las rocas más proclives a la descalcificación en este ámbito son las calcarenitas del Langhiense-Serravalliense, las calizas margosas del Barremiense, las calizas del Albiense y las dolomías del Cretácico Superior.

Esta litología se ve afectada por una considerable humedad en el semestre invernal, cuando se producen las precipitaciones, que empapan las rocas ay udadas por la presencia de una importante cubierta vegetal y una densa red de fracturas. El volumen actual de las lluvias oscila entre los 350 mm de las zonas más áridas y los 550 mm de las más húmedas. Son precip itaciones moderadas que cobran importancia al producirse en el período de mínima evap otranspiración, y que durante el período invernal permiten la aparición de verdaderas zonas húmedas en las elevadas umbrías de las sierras de la comarca.

Por otro lado, la frecuente disposición tabular, o subtabular, de las estructuras del relieve, en especial de las grandes mesas cretácicas, junto a la poco 
jerarquizada red de avenamiento, con un marcado nivel de base local, potencian la infiltración de las aguas en el roquedo y, con ella, los procesos de disolución. Así, el endorreísmo endémico de la comarca ha posibilitado la formación de grandes sumideros a través de los cuales se produce el avenamiento hip ogeo. En este sentido hay que hacer una distinción clara entre cubetas endorreicas de origen estructural o morfológico, ajenas en todo caso en su configuración a la disolución de las calizas, sobre las que después se ha instalado un avenamiento hip ogeo de tipo kárstico, y cubetas endorreicas debidas a la acción del karst sobre las rocas calizas, en la que ha labrado hondonadas por disolución, que se ajustan al esquema característico de las dolinas.

Entre las primeras formas destaca el sumidero de la Hoya de la Carrasca, donde la isohipsa de $680 \mathrm{~m}$ encierra una cubeta de $12^{\prime} 25 \mathrm{~km}^{2}$, con un potente paquete de sedimentos cuaternarios que tapizan el fondo de la depresión y ocultan las calizas del Albiense infray acentes, por entre las cuales se produce el avenamiento hip ogeo. Se trata de una gran cuenca estructural en cuyo fondo, sobre la confluencia de los glacis, con los aguaceros de fuerte intensidad horaria se forma una extensa laguna, que desaparece a los pocos días al infiltrarse el agua por entre los materiales cuaternarios de la superficie primero y, después, por las calizas infrayacentes. Su condición de aliviadero subválveo ha sido aprovechada para canalizar hacia esta hoya las aguas que, tras los fuertes chubascos de otoño y primavera, inundan la cubeta endorreica de las Juncadas, con un nivel impermeable marcado por el afloramiento triásico Ayora-Almansa, donde se ha instalado el área de cultivos regados de esta ciudad. Con todo, hay que señalar que el espesor de los sedimentos cuaternarios que cubren el fondo de la Hoya de La Carrasca aumenta con cada aguacero, y las arcillas y limos depositados, que dibujan un suave perfil cóncavo, dificultan cada vez más el desagüe

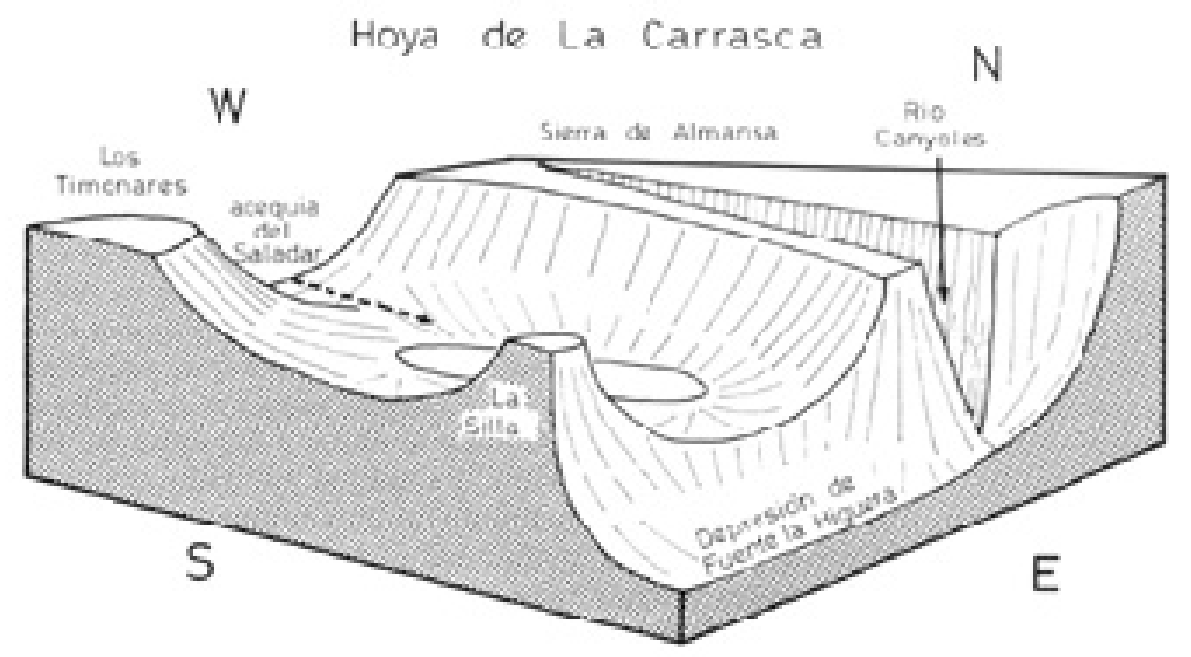

FIgURA 6. Bloque diagrama de la Hoya de La Carrasca, sumidero kárstico. 
en profundidad. De ahí que las aguas permanezcan en superficie durante algunos días.

Sumideros de características morfológicas similares se encuentran en Las Hoy as de Catín y en Los Pozuelos, sobre las calizas del Cretácico entre Almansa y la Sierra de la Oliva, colgados a $880 \mathrm{~m}$ de altitud y en Amperes, a 720 m, al pie del Cerro de los Sumideros -topónimo harto elocuente-. De ellos, el de Las Hoy as de Catín es el menos proclive a enlagunarse, lo que hace suponer un espesor mínimo del paquete cuaternario superior y un rápido avenamiento subterráneo.

La gran horizontalidad de los estratos calcáreos de la comarca, dispuestos con frecuencia en forma de mesas, es uno de los factores que potencian los procesos del karst. Sobre ellos la disolución kárstica ha labrado profundas hondonadas de formas redondeadas, que constituyen pequeñas cubetas endorreicas con un desagüe subterráneo en todos los casos. Se trata de dolinas con la fisonomía alterada por las continuas labores agrícolas que se desarrollan en su seno: los fondos están labrados y ocupados por cereales y las paredes suavizadas por estas tareas, por los derrubios de ladera y por los depósitos aluviales del agua de escorrentía.

Entre estas formas destacan las desarrolladas sobre las calizas del Kimmeridgiense que constituyen la sup erficie del horst de Bonete, donde la disolución kárstica ha labrado una serie de dolinas, con formas redondeadas y de dimensiones que no exceden los $1.000 \mathrm{~m}$ de diámetro, alineadas entre Bonete y Las Casas de Delgado, configurando una sucesión de cuatro pequeñas cuencas endorreicas que rompen el aspecto amesetado del horst; tres de ellas reciben el significativo nombre de Hoya: Hoya Morena, Hoya Escobosa y Hoya Labrada; y la cuarta se encuentra entre Las Riscas y La Sima. Sus fondos, entre cinco y diez metros por debajo del nivel del horst, están roturados y la arcilla residual de la disolución mezclada con los depósitos aluviales. La existencia de un avenamiento hipogeo queda confirmada por la presencia de una gran caverna en la dolina de La Sima (que da nombre al paraje), conocida desde antiguo y que ya describe Madoz:

«... y junto a Las Casas del Delgado se encontró una caverna toda incrustada de estalactitas y estalagmitas blancas, de caprichosas figuras y casi transparentes como la loza...» ${ }^{10}$.

Sobre los materiales del Trías se observa también la presencia de formas del modelado kárstico. Por un lado, la descalcificación ha sido intensa en las dolomías y calizas dolomíticas, cebándose en las figuras y líneas de diaclasamiento, dejando un paisaje residual de formas redondeadas que constituyen pequeñas cresterías de morfología ruiniforme, a menudo culminando paquetes de arcillas y margas. Por otro lado, la disolución ha afectado también a las sales de los materiales del Keuper, arcillas y yesos, sobre los que se ha desarrollado la morfología típica de cárcavas de formas redondeadas o cóncavas; se trata del karst salino, responsable también de la configuración de algunas ramblas que atraviesan la serie de apretados estratos triásicos de la alineación Alpera-Montealegre, labrando pequeños cañones muy poco encajados y de fondo plano, aunque la may or parte de los cursos aprovechan fracturas y desgarres para flanquear el Trías. Sin duda, las formas más espectaculares del karst sobre esta 
litología son las simas, oquedades y grietas abiertas sobre los delgados estratos de calizas dolomíticas y dolomías con un gran desarrollo en profundidad. Bocas de sima, de aspecto diaclasado y rocas muy lavadas, aparecen en la pequeña alineación de dolomías del Rethiense-Hettangiense en Casa Ortina, en las calizas dolomíticas del Keuper en el cerro del Castillo de Montealegre y en las calizas del Muschelkalk en el cerro del Castillo de Almansa. Ninguna de ellas ha sido todavía explorada, aunque se han llevado a cabo incursiones de hasta unos centenares de metros, comprobándose el fluir de las aguas al menos esporádicamente.

\section{NOTAS BIBLIOGRÁFICAS}

1 DANTIN CERECEDA, J., «La aridez y el endorreísmo español. El endorreísmo bético», Estudios Geográficos, Madrid, n. ${ }^{\circ}$ 1, 1940, pp. 75-117.

2 DANTIN CERECEDA, J. y REVENGA CARBONELL, A., «Las líneas isoxeras de España según los índices termopluviométricos. Avance del estudio de la aridez en España», Estudios Geográficos, n. ${ }^{\circ}$ 2, Madrid, 1941, pp. 35-91.

3 MORALES GIL, A., El Altiplano de Jumilla-Yecla, Murcia, Univ. de Murcia, 1972, 179 pp.

ROSSELLO VERGER, V. M., «Los llanos y piedemontes: un dominio subárido», Geografía de la Provincia de Alicante, Alicante, Dip. Prov., 1978, pp. 37-76.

MATARREDONA COLL, E., El Alto Vinalopó. Estudio geográfico, Alicante, I.E.A., 1983, 370 pp., p. 79.

4 MONKHOUSE, F.J.,Diccionariodetérminos geográficos, Barcelona, Oikos-Tau, 1978, 560 pp., p. 187. La transpiración de una sola planta de maíz entre mayo y septiembre ha sido evaluada en más de 200 litros. 